\title{
Gestão por competências no setor público: experiências de países avançados e lições para o Brasil
}

Ethel Airton Capuano

Ministério do Planejamento, Orçamento e Gestão (MP)

A complexidade crescente das sociedades democráticas do século 21 exige dos governos soluções que os modelos contemporâneos de gestão pública não são capazes de esboçar. Como se observa nas experiências de países mais avançados, a tecnologia social denominada "gestão por competências" tem sido utilizada, nas últimas três décadas, nos setores privado e público como uma verdadeira plataforma metodológica para gestão meritocrática de mudanças em busca de melhor desempenho. Dessas experiências reformistas podem-se extrair importantes lições para reflexões acerca da possibilidade de implementação de modelos de gestão baseados em competências no contexto do setor público brasileiro.

Palavras-Chave: gestão por competências, administração pública, gestão de pessoas, modelo de gestão, cooperação internacional

\section{Gestión por competencias en el sector público: experiencias de países avanzados y lecciones para Brasil}

La creciente complejidad de las sociedades democráticas del siglo 21 requiere soluciones de los gobiernos que los modelos de gestión pública contemporáneos no son capaces de dibujar. Como se señaló en las experiencias de los países más desarrollados, la tecnología social Ilamada "gestión de competencias" se ha utilizado, en las últimas tres décadas, en

[Artigo recebido em junho de 2014. Versão final em dezembro de 2014.] 
el sector público y el sector privado como una verdadera plataforma metodológica para la gestión meritocrática de cambios en busca de un mejor rendimiento. De tales experiencias de reforma pueden extraerse importantes lecciones para las reflexiones sobre la posibilidad de implementación de modelos de gestión por competencias en el contexto del sector público brasileño.

Palabras-Clave: gestión por competencias, administración pública, gestión de personas, modelo de gestión, cooperación internacional

\section{Competency management on the public sector: experiences from developed countries for} Brazil

The increasing complexity of democratic societies of the 21st century requires governmental solutions that contemporary models of public management are not able to sketch. As noted in the experiences of more developed countries, social technology called "Competency Management" has been used in the last three decades in both the private and public sectors as a true methodological platform for meritocratic change management in search for better performance. From such reformist experiences one can draw important lessons for reflections on the possibility of implementing management models based on competencies in the context of the Brazilian public sector.

Keywords: competency management, public administration, human resources management, management model, international cooperation 
A cultura é o buraco da agulha pelo qual as mudanças devem passar.

(WESTMAN, 2012)

\section{Introdução}

A Gestão por Competências representa o que se poderia denominar uma "tecnologia social" (LASSANCE, JR. et al., 2004; PETERS, 2010) bastante robusta para empreender avaliações meritocráticas sobre os trabalhadores na prática, contribuindo para a solução de um dos principais problemas apontados pelos especialistas em modelos tradicionais de gestão de pessoas nas organizações: a falta de critérios objetivos para mensuração da capacidade profissional e do desempenho individual (LUCIA; LEPSINGER, 1999).

Caso se assuma o raciocínio em que pessoas, processos, tecnologia e cultura organizacional são os pilares ontológicos da gestão, e que pessoas são a base dos demais, então também se poderá assumir que a gestão por competências é um modelo de gestão de espectro amplo nas organizações. Suas características técnicas contribuem para a objetividade, transparência e democracia nas avaliações profissionais, atributos considerados como as ambições mais caras de qualquer sistema de gestão que busque a justiça social no ambiente das organizações no século 21.

Esse modelo de gestão também apresenta uma característica notável quanto à sua utilidade: ele pode extrapolar os limites epistemológicos da capacitação e do desenvolvimento e subsidiar também as demais etapas do ciclo de gestão de pessoas, oferecendo parâmetros mais técnicos e realistas para o planejamento da força de trabalho, recrutamento e seleção, remuneração, avaliação e retribuição por desempenho, promoção, apontamento para cargos de alta gestão e sucessão.

Entretanto, sua introdução no ambiente das organizações do setor público apresenta problemas diversos daqueles enfrentados nas organizações privadas, exigindo reflexões mais qualificadas para a compreensão de suas implicações. O texto a seguir tem como primeiro objetivo promover esse debate necessário, de um ponto de vista mais técnico e realista, sobre a gestão por competências quando aplicada em larga escala nos sistemas de gestão de pessoal civil dos governos no Brasil.

Com o presente artigo, resultado de pesquisa na literatura especializada, em relatórios publicados pelos governos de países mais avançados da Organização para Cooperação Econômica e Desenvolvimento (The Organization for Economic Co-operation and Development - OECD), e nas conclusões de um esforço de consultoria internacional patrocinado pela Secretaria de Gestão Pública do Ministério do Planejamento, Orçamento e Gestão (Segep/MP) em 2013, no âmbito do Programa Diálogos Setoriais União Europeia - Brasil, pretende-se contribuir 
para o esclarecimento de aspectos cruciais ao processo de adoção dessa tecnologia social em larga escala nos sistemas de pessoal civil no setor público brasileiro. 0 texto apresenta algumas respostas para as seguintes questões:

I. Em que contextos e com quais propósitos os governos de países da OECD adotaram a gestão por competências?

II. Como se iniciaram os processos de implantação dessa metodologia de gestão de pessoas no setor público e como evoluíram desde então?

III. Quais as implicações da gestão por competências para o setor público brasileiro, considerando suas características institucionais e culturais?

\section{Estado da arte em países mais avançados}

O conhecimento histórico das experiências de até três décadas dos governos de países mais desenvolvidos, tais como os membros da OECD, representa um importante insumo epistemológico para a evolução dos estudos, pesquisas e experiências sobre a implantação de modelos de gestão por competências no setor público.

\section{Bélgica}

O movimento da gestão por competências no setor público da Bélgica revela uma trajetória bastante peculiar: iniciou-se num governo regional e não no governo central. Conforme Hondeghem e Parys (2002), o governo flamengo (de Flandres) assumiu a liderança no início desse movimento na Bélgica, observando-se que no governo federal belga o desenvolvimento de um modelo de gestão baseado em competências se deu de forma muito mais lenta, sendo a dupla cultura do país (uma típica da região de Flandres, ao norte, e outra de Valônia, ao sul) considerada um elemento dificultador.

É importante compreender-se o contexto histórico que propiciou esse movimento pela competência, que se iniciou em 1988 com a terceira reforma do Estado belga, caracterizada pela devolução de autonomia às administrações regionais. Essa reforma culminou, em 1993, com uma ampla reforma do ordenamento institucional de gestão de pessoas vigente à época, quando 100 decretos reais e decisões ministeriais acumulados desde o antigo Estatuto Camu de 1937 foram substituídos por um novo regulamento geral para gestão de pessoas: o Estatuto de Pessoal Flamengo (HONDEGHEM; PARYs, 2002). As principais inovações desse novo estatuto foram: novas regras de recrutamento e promoção baseadas em descrições de postos de trabalho e perfis de competências, novo sistema padrão de avaliação dos servidores, novo sistema de carreiras e redução no número de classes e padrões de progressão e respectivas escalas de remuneração. 
O que essa história tem de mais relevante, no entanto, são os objetivos da reforma iniciada nos anos 1990 e a estratégia engendrada pelo governo belga para sua execução: utilizar a gestão por competências como instrumento de apoio a um sistema de gestão do desempenho no setor público. Esse sistema de gestão do desempenho, denominado PLOEG (acrônimo nativo para planejamento, liderança, acompanhamento, avaliação e retribuição), era considerado crítico para o êxito do movimento reformista, tendo sido concebido como um instrumento integrado de gestão de pessoas na administração flamenga (HONDEGHEM; PARYS, 2002).

Esse modelo de gestão do desempenho se baseava em 45 famílias de funções que serviam de eixos para os diagnósticos de competências dos servidores públicos, inclusive dos integrantes da alta gestão. As descrições dos postos de trabalho e os respectivos perfis de competências são considerados, nesse sistema de gestão do desempenho, uma espécie de âncora conceitual com a missão de emprestar estabilidade temporal ao sistema, restando, no entanto, uma parcela de flexibilidade instrumental na definição dos objetivos anuais definidos para as organizações. Esse sistema de avaliação de desempenho era considerado justo e honesto, sem o viés meramente punitivo tradicional, e os servidores se autoavaliavam, eram avaliados e avaliavam as chefias a partir de uma pactuação inicial de resultados esperados.

Com o movimento reformista flamengo, a descentralização administrativa dos anos 1990 exigia também o desenvolvimento de novas competências nos servidores, antes desnecessárias no modelo anterior de gestão pública centralizado. Esse cenário também exigia do governo flamengo uma visão-perspectiva de longo prazo, no sentido de prover os servidores públicos de competências para lidar não somente com os problemas presentes, mas também com desafios futuros. Os valores essenciais exigidos de todos os servidores seriam, inicialmente, quatro: orientação ao cliente, confiabilidade, colaboração e melhoria contínua. E as categorias de competências exigidas dos membros da alta gestão seriam: visão, direcionamento, delegação, capacidade de persuasão, empatia em 360 e conhecimento de gestão em contextos de governo. Essas categorias deveriam, então, ser traduzidas em competências comportamentais em cada contexto organizacional do governo federal belga (HONDEGHEM; PARYS, 2002).

Finalmente, o pioneirismo flamengo levou o governo federal belga, após a radical reorientação política no país resultante das eleições de 1999, a adotar também a gestão por competências como instrumento de um amplo programa de reformas administrativas consolidado no conhecido "Plano Copérnico", metáfora inspirada em Nicolau Copérnico, astrônomo polonês que mostrou que era a Terra que girava em torno do Sol e não o contrário. O objetivo dessa metáfora foi provocar uma reorientação dos valores do serviço público belga, que deveria, doravante, ser 
menos burocrático, confuso e pesado e mais voltado ao atendimento dos cidadãos (mediante analogia com a teoria heliocentrista de Copérnico, pode-se concluir que o Sol seria como o cidadão e a Terra como a burocracia do setor público belga).

Considerando que uma nova mentalidade em gestão pública era considerada crucial para o êxito do Plano Copérnico, outras impactantes mudanças eram previstas na gestão de pessoas, tais como (HONDEGHEM; PARYS, 2002):

a. planejamento da força de trabalho com base em descrições de postos de trabalho e perfis de competências, como no modelo flamengo (tanto no nível técnico como gerencial, inclusive na alta gestão);

b. abertura do sistema de recrutamento e seleção, para os dois mais altos níveis de gestores públicos, a candidatos do setor privado, mediante o uso de agências especializadas em processos seletivos de executivos;

c. renovação completa da média gestão nos órgãos; e

d. valorização dos especialistas, abrindo uma alternativa de desenvolvimento e progressão na carreira que não pela via da ascenção aos postos de gerência (modelo conhecido como "carreira em Y").

Em termos de avaliações de competências dos servidores, esse modelo previa dois elementos ou categorias: competências técnicas, avaliadas em testes práticos, e competências comportamentais, avaliadas em entrevistas (mediante o uso de método de eventos comportamentais). Op de Beeck e Hondeghem (2010a) ressaltam que esse novo modelo belga de gestão de pessoas provê ao serviço público federal daquele país uma imagem mais atrativa em termos de mercado de trabalho, mas que a intenção é a introdução de mudanças no sistema de carreiras, criando também uma linguagem comum para o diálogo acerca do tema.

O caso belga também ilustra como o contexto político, econômico, social e cultural de um país é determinante para a modelagem de seu sistema de gestão por competências. Devido à escassez de profissionais com diplomas de interesse para as carreiras do setor público no mercado, o sistema de recrutamento e seleção está tentando substituir os requisitos de qualificação formal, baseado em diplomas emitidos pelo sistema educacional, por requisitos de competências demonstráveis pelos candidatos em exames práticos. Esse novo modelo de recrutamento e seleção iniciou-se com um projeto-piloto em 2008, destinado a selecionar especialistas em tecnologias da informação e comunicação (TIC), cujas lições aprendidas encorajaram o governo a estendê-lo para outras áreas de competências. Contudo, críticas pairam sobre esse modelo devido ao risco do nepotismo no processo seletivo e o governo belga deverá utilizá-lo apenas quando se identificar escassez de um determinado perfil profissional no mercado (OP DE BEECK; HONDEGHEM, 2010a). 
Outro aspecto importante do modelo belga se reporta às conexões entre capacitação e desenvolvimento, certificação profissional e retribuição pecuniária. A cada seis ou oito anos, os servidores públicos de níveis $A$ a $D^{1}$ podem, voluntariamente, inscrever-se em treinamentos certificados pelo governo federal, para atualização e desenvolvimento de competências, que é o único caminho para o desenvolvimento individual nas carreiras. Os conteúdos desses treinamentos são de uso geral, exigidos de todos os servidores públicos federais, e os testes visam examinar o nível de conformidade do candidato em relação aos objetivos de aprendizagem predefinidos.

Em alguns casos em que o treinamento é aberto a servidores de diferentes níveis, os níveis de dificuldade dos testes também são diferenciados. Entretanto, a inovação fica por conta da retribuição que os servidores recebem quando atingem os níveis mínimos de aproveitamento nesses treinamentos, que pode ocorrer de duas maneiras: um bônus por competência (competency allowance); ou uma promoção para um nível salarial maior. Ou seja, eles podem receber um prêmio pago apenas uma vez ou um acréscimo salarial permanente. Esse sistema de retribuição por treinamentos tem sido, no entanto, criticado porque alguns entendem que ele solapa o sistema de avaliação de desempenho, na medida em que não se baseia em resultados concretos (ou entregas) de trabalho dos servidores (OP DE BEECK; HONDEGHEM, 2010a).

Op de Beeck e Hondeghem (2010b) ilustram o atual modelo de competências do governo federal da Bélgica, denominado "Modelo de Competências $5+1$ ", conforme a Figura 1. Esse modelo consiste de cinco agrupamentos (clusters) de competências genéricas e um agrupamento (cluster) de competências técnicas, sendo que se entende por competências genéricas as competências comportamentais que são exigidas, em maior ou menor grau, em cada função, mas que não são diretamente conexas aos postos de trabalho. Como competências técnicas, entendem-se os conhecimentos e habilidades específicos e necessários para o desempenho dos servidores em seus postos de trabalho. Esse modelo, adotado a partir de 2009, incorporou as competências essenciais (core competencies) anteriormente definidas em cada agrupamento de competências, cujas categorias de competências que os compõem são escalonadas em níveis de complexidade e impacto. Essas competências essenciais (na verdade, categorias de competências essenciais) eram: serviço, colaboração, lealdade, orientação a resultados e desenvolvimento pessoal.

\footnotetext{
1 O nível "A" se refere aos membros da alta gestão, que no governo belga é composta pelos dirigentes (conselheiros, diretores e diretores-adjuntos), diplomatas, engenheiros, cientistas da computação (informaticien) e médicos; o nível " $\mathrm{B}$ " se refere aos cargos de chefia intermediários (gerentes), programadores de computador e especialistas em geral; o nível " $C$ " se refere aos gerentes e técnicos que atuam em funções técnicas (exceto as incluídas no nível "B"); e o nível “D” aos cargos de apoio operacional (BELgIQUe, 2014; SANCHES, 2014).
} 


\section{Figura 1: Modelo de Competências do Governo Federal da Bélgica}

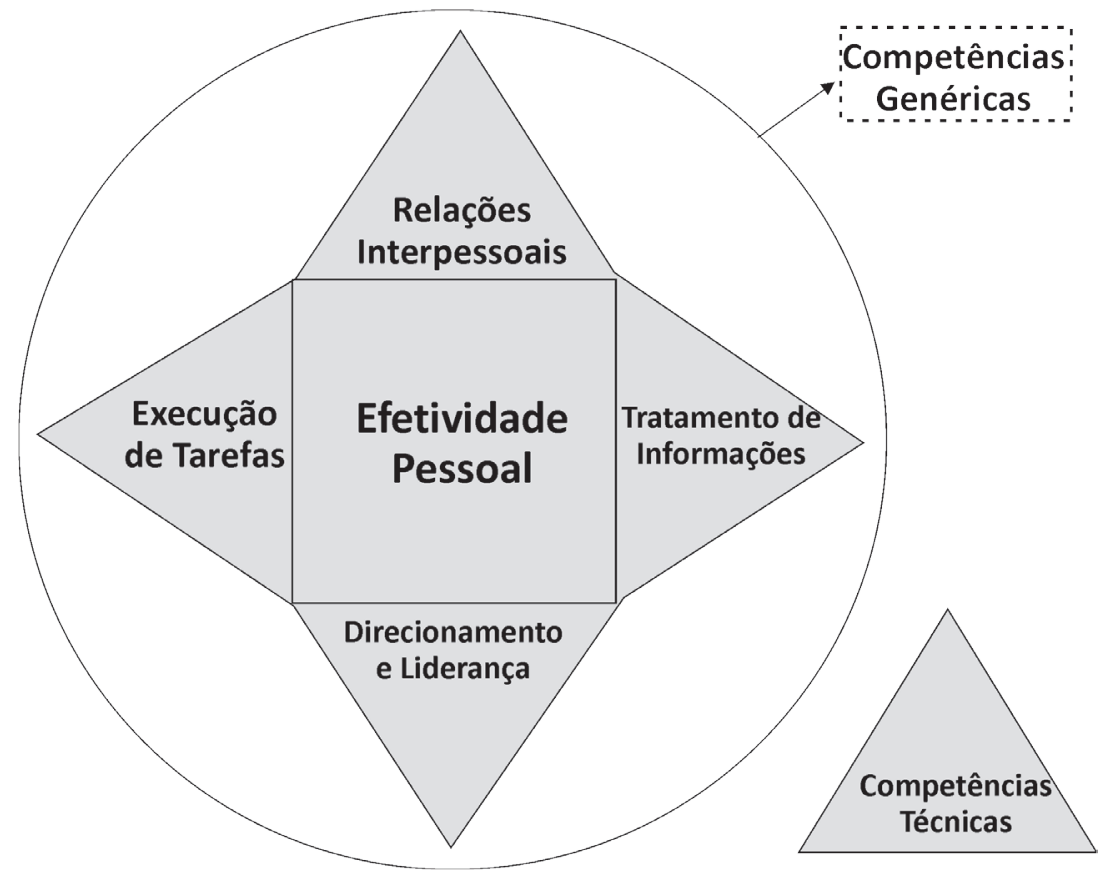

Fonte: Op de Beeck e Hondeghem, 2010b.

Essas categorias de competências não são definidas, tecnicamente, para serem observadas, exigindo-se mais um passo metodológico para que possam ser observadas num contexto de trabalho, de acordo com a proposta sintática de Brandão (2012), em que uma competência deve ser definida com um verbo, mais um objeto de ação (conexo ao verbo), mais uma condição e/ou um critério específico de contexto ou posto de trabalho.

O modelo de competências do governo belga, bastante coerente com seus objetivos estratégicos de mudança do ethos no serviço público, também aponta para competências futuras a serem desenvolvidas. Essas competências se referem a uma visão de futuro que se consubstancia como política de desenvolvimento de pessoas, tendo como pilares conceituais: serviços públicos orientados ao cliente; serviços públicos responsáveis, efetivos e orientados a resultados; um setor público como empregador atrativo, dinâmico e inovador; um governo integrado.

Op de Beeck e Hondeghem (2010b) identificam, a partir desses pilares conceituais de competências, o perfil genérico dos servidores públicos do futuro na Bélgica: orientados à qualidade; orientados ao cliente; responsáveis; efetivos; e orientados a resultados. 


\section{Estados Unidos}

O país pioneiro no desenvolvimento de uma nova visão da gestão por competências nas organizações começou a introduzir essa tecnologia social no seu setor público em 1990, quando o Escritório de Gestão de Pessoas (US Office of Personnel Management) do governo federal iniciou um trabalho de desenvolvimento do primeiro modelo comum de competências governamental. Esse trabalho consumiu dois anos, apresentando como resultado o Construto de Efetividade da Liderança (Leadership Effectiveness Framework). O objetivo do órgão central de gestão de pessoas era a unificação da própria linguagem de competências entre as agências, associando os resultados da tradicional análise de postos de trabalho (job analysis) a um modelo de competências (GETHA-TAYLOR, 2010; OP DE BEECK; HONDEGHEM, 2010a).

Com um ethos mais científico, que buscava evidências empíricas para generalizações, o Escritório de Gestão de Pessoas dos Estados Unidos da América (EUA) patrocinou uma pesquisa (Leadership Effectiveness Survey) com entrevistas de mais de 10 mil executivos, gerentes e supervisores do governo federal, buscando conhecer os fatores que determinam a efetividade no desempenho em postos de trabalho.

Conforme Op de Beeck e Hondeghem (2010a), essa pesquisa resultou numa lista de 22 competências de liderança, incluindo algumas competências bastante conhecidas: comunicação por escrito, comunicação oral, solução de problemas, habilidades interpessoais, gestão de uma força de trabalho com diversidade, visão, pensamento criativo, flexibilidade, decisão, liderança, gestão de conflito, autodireção, influência/negociação, planejamento e avaliação, gestão financeira, gestão de recursos humanos, orientação ao cliente, consciência sobre o ambiente externo, montagem de equipes, gestão de tecnologias, controles internos (integridade), competências técnicas.

Essas competências seriam agrupadas em cinco grandes clusters e exigidas de todos os servidores públicos, mas com graus de importância diferentes dependendo do nível do cargo. Cabe salientar que o governo federal dos EUA não tem um sistema de carreiras, mas de cargos. Oportuno destacar, também, que agrupamentos de competências elementares como comunicação escrita e comunicação oral constituíam dois desses cinco clusters de competências.

Em 1998, observando as inovações de gestão no setor privado, tais como downsizing e reengenharia, o Escritório de Gestão de Pessoas (US Office of Personnel Management) atualizou esse modelo, surgindo então o Modelo de Competências de Liderança 1998 (1998 Leadership Competency Model), que confirmou as 22 competências do modelo original e identificou cinco novas competências: empreendedorismo, parceria, resiliência, habilidade política e motivação para o serviço público. Op de Beeck e 
Hondeghem (2010a) observam que, nesse novo modelo, as 27 competências foram agrupadas em cinco metacompetências: liderando a mudança, liderando pessoas, orientação a resultados, visão de negócio e construindo coalizões/comunicação. Essas metacompetências também serviram como base para o construto de competências denominado Qualificações Essenciais Executivas (Executive Core Qualifications), desenhado para o estamento da alta gestão pública nos EUA - o Serviço Executivo Sênior (Senior Executive Service).

É importante uma explanação do conceito de "liderança" dos construtos de competências dogoverno federal dosEUA, pois esse conceitonão pode ser confundido com o de gerência, aproximando-se mais do conceito de empreendedorismo. Nessa visão, a liderança desejada não deve se manifestar, necessariamente, num determinado estamento gerencial dos postos de trabalho, mas a partir de ideias formuladas por qualquer servidor público capaz de propor e empreender mudanças produtivas em seu ambiente laboral. Op de Beeck e Hondeghem (2010a), citando um relatório de 1999, ressaltam que na visão de competências essenciais executivas dos EUA, ante um mundo caracterizado por rápidas mudanças no serviço público, as competências, atributos e comportamentos de liderança são mais importantes que as competências gerenciais.

O Escritório de Gestão de Pessoas dos EUA, no final dos anos 1990, aplicou uma abordagem denominada Inventário Multipropósito de Análise de Sistemas Ocupacionais - Finalizado-Fechado (Multipurpose Occupational Systems Analysis Inventory - Closed-Ended-MOSAIC) $)^{2}$ para produzir uma lista com 37 competências gerais para toda a força de trabalho do governo federal (USOPM, 2013). Como se pode observar nos conteúdos desse construto, ele se parece com um dicionário de competências, em que cada competência é definida com um verbete sintático que pretende esclarecer sua natureza.

Emboracom maisênfase em desempenhoe resultados do que no desenvolvimento de competências per se, os modelos de gestão de pessoas do governo federal dos EUA prescrevem competências que devem explicar o desempenho superior desejado dos servidores públicos. Em ocupações consideradas de missão crítica, essas competências prescritivas são utilizadas em várias etapas ou funções do ciclo de gestão de pessoas, tais como planejamento da força de trabalho, recrutamento,

\footnotetext{
${ }^{2}$ Essa metodologia de análise de postos de trabalho tem sido desenvolvida pelo Escritório de Gestão de Pessoas do governo federal dos EUA com objetivo de automação dos processos de coleta e tratamento de dados de servidores públicos e respectivos supervisores em muitas ocupações do setor público, para uso em várias funções da gestão de recursos humanos.
} 
seleção, desenvolvimento de pessoas e retenção de talentos. Outra área de fundamental importância para as organizações públicas nos EUA, que também se beneficia da gestão de competências, é a de soluções tecnológicas.

\section{França}

A introdução da gestão por competências no setor público francês exigiu mais de uma década de experiências e debates para se tornar realidade. Esse tempo se justifica pela forte tradição democrática do modelo de processo seletivo para ingresso no serviço público daquele país, baseado no concurso público de provas de conhecimento acadêmico. Como consequência da disparidade estrutural entre requisitos de competências para ingresso e requisitos de competências para o desempenho efetivo nos postos de trabalho, algo comum nos sistemas de carreiras, Jeannot e Lichtenberger (2002) relatam uma tensão constante, no final dos anos 1990, entre os defensores dos egressos da Ecole Polytechnique e da Ecole Nationale d'Administration, que constituem a elite intelectual do serviço público francês, e os defensores dos servidores públicos que adquirem competências profissionais pela experiência.

O relatório de Jeannot e Lichtenberger (2002) registra que apenas alguns órgãos públicos franceses reconheciam, no início do século 21 , que as profissões evoluem e que o treinamento, recrutamento e gestão de pessoas devem acompanhar essa evolução. E nessa época, a iniciativa que continha uma semente, ainda que tímida, da gestão por competências no governo francês era um projeto de planejamento do Ministério do Serviço Civil denominado Gestion Prévisionelle dês Effectifs, des Emplois et des Compétences (GPEEC), algo como Gestão da Previsão de Efetivos, Empregos e Competências. Esse projeto tinha como objetivo a coleta de informações sobre iniciativas de desenvolvimento de pessoas nos ministérios, abordando seis diferentes aspectos: inventário de recursos humanos disponíveis; projeções de médio prazo sobre aposentações; identificação de missões futuras e respectivos postos de trabalho; consequências em relação ao número de empregados; análises de discrepâncias entre tendências e necessidades; e propostas para redução dessas discrepâncias.

Conforme Sanches (2013), o início formal dos esforços do setor público francês em direção à gestão por competências ocorreu em agosto de 2001, com a promulgação da Lei de Orientação Relativa às Leis de Finanças (Loi Organique Relative aux Lois de Finances - $L O L F)$, que embasou uma reforma no serviço público orientada para o alcance de melhores patamares de desempenho. Essa reforma propunha métodos e práticas gerenciais e comportamentos profissionais orientados para resultados, fazendo com que todos os níveis de gestão (começando pelo topo, na alta gestão) e instâncias administrativas envolvidas se mobilizassem, de maneira transparente, responsável e eficaz, para a obtenção de um conjunto de resultados projetados. 
Essa iniciativa previa um planejamento estratégico de abrangência governamental com desdobramentos em cascata, em que o governo francês se comprometia, diante do Parlamento, a levar a cabo um certo número de missões associadas às políticas públicas sob sua responsabilidade. A LOLF, no entanto, somente veio a ser integralmente aplicada em 2006, quando essas missões (desdobradas em programas que são, por sua vez, "quebrados" em ações) foram identificadas e apresentadas, de maneira transparente, no orçamento anual do Estado francês. $O$ modelo de planejamento decorrente da LOLF se assemelha ao plano plurianual de investimentos (PPA) do Governo Federal do Brasil, em que se especifica, em cada um dos programas de intervenção, um pequeno número de objetivos (em geral, um ou dois objetivos por programa) e, em relação a cada um desses objetivos, são escolhidos e mencionados um ou alguns indicadores.

Outra inovação importante foi a associação de objetivos e metas a patamares de desempenho mediante uma pactuação anual. Sanches (2013) ressalta que essas metas negociadas são um dos elementos importantes levados em conta na avaliação do desempenho individual dos agentes públicos, das equipes e das diferentes unidades organizacionais no serviço público francês.

Nesse novo contexto, os métodos de gestão das forças de trabalho das três componentes da administração francesa (administração do Estado, territorial, hospitalar) foram revistos e reajustados, impondo-se, a partir de 2006 e de maneira progressiva, uma perspectiva estratégica na gestão de recursos humanos. Como medidas estratégicas, concentraram-se esforços na promoção de uma gestão integrada de pessoas, gestão de competências, simplificação do sistema de carreiras, promoção da mobilidade interna e externa, avaliação de desempenho (individual e de equipes) e na introdução de componentes salariais associados à qualidade do desempenho.

Em termos de gestão de pessoas, tem-se como marcos desse movimento reformista o lançamento da Escola de Gestores de Recursos Humanos, que consiste de uma rede interministerial de atores apoiando os gestores de pessoas nos ministérios; da implementação de um acordo sobre a formação ao longo da vida, que transpôs para a função pública o direito individual à formação e introduziu o reconhecimento da experiência profissional; e do sistema de avaliação de desempenho dos servidores.

Sanches (2013) observa que a gestão de competências é um dos componentes metodológicos importantes do novo modelo de gestão de pessoas do governo francês, que se reorganiza de modo a poder contribuir eficazmente para a gestão estratégica do setor público, orientada para resultados e adotada nos diferentes patamares gerenciais: nível do governo, dos ministérios, das direções e das equipes. Com esse objetivo geral, 
as forças de trabalho dos órgãos públicos são administradas nas óticas provisional (no sentido de prover recursos) e estratégica, de modo a reunirem e manterem níveis adequados de motivação (em outras palavras, o querer bem fazer), de competências (o saber fazer), de organização (o poder fazer) e de consciência profissional (o sentido das responsabilidades e da ética), associados a um entendimento claro dos níveis de desempenho e comportamentos profissionais esperados.

Conhecendo-se o problema da eminência das aposentações em massa que também paira sobre o setor público francês, compreende-se a importância da dimensão habilidade em seu modelo de competências. Conforme Sanches (2013), a gestão de competências no modelo francês é centrada sobre a preservação e o desenvolvimento de conhecimentos e do saber fazer, intimamente associada à gestão da formação dos servidores públicos. Entretanto, esse modelo de gestão de pessoas não é ingênuo como os modelos que se originam apenas da visão isolada de pessoas nas organizações. Ele não ignora a importância de outros três fatores que, associados às pessoas, determinam o nível de desempenho das organizações públicas: motivação, organização (estruturas) e processos de trabalho. A motivação se relaciona ao desejo de bem fazer; as competências à capacidade de bem fazer; e a organização à possibilidade de bem fazer, incluindo-se nesse fator também os processos produtivos e suas tecnologias.

Sanches (2013) ressalta que a Gestão Provisional dos Efetivos, dos Empregos e das Competência (GPEEC) não é excessivamente centralizada, deixando aos diferentes órgãos governamentais uma ampla margem de manobra. Cada órgão pode orientar, dentro do quadro de regras e princípios de base estabelecidos para o conjunto do aparelho governamental, a sua política de valorização e de desenvolvimento de pessoas. Essa autonomia é exercida com base em regras, que são estabelecidas e geridas pelo órgão central do governo (órgão "reitor"), que tem o mandato e a responsabilidade de administrar toda a função pública na França.

Evidencia-se essa autonomia controlada com a abordagem compartilhada de elaboração e utilização harmônica dos empregos e competências de referência (Référentiel d'Emplois et de Compétence - REC). Esses referenciais são elaborados combinando-se e integrando contribuições em três níveis: do órgão central do sistema; das direções de recursos humanos dos ministérios setoriais; e das unidades de gestão de recursos humanos periféricas (nas unidades administrativas onde os servidores públicos atuam, efetivamente).

O processo de construção de um modelo referencial de empregos e competências, na tradição da função pública francesa, é abrangente, coerente e metódico, culminando numa estrutura arborescente. Essa estrutura combina especificações que são sucessivamente deduzidas, pelos órgãos usuários, a partir de uma base 
estabelecida pelo órgão central de gestão de pessoas, ou, na periferia do sistema, a partir das especificações de cada órgão setorial para suas unidades.

Em suma, as instâncias que intervêm na elaboração dos referenciais representam três níveis hierárquicos diferentes de gestão. O órgão central é o primeiro a intervir, preparando dois documentos de referência importantes: o Repertório Interministerial das Profissões do Estado (Répertoire Interministériel des Métiers de l'État-Rime) e o Dicionário Interministerial das Profissões do Estado (Dictionnaire Interministériel des Compétences des Métiers de l'État - DICME), esse último associado ao primeiro. $\mathrm{O}$ Rime é o documento básico de referência que descreve os grandes tipos fundamentais de empregos que se podem identificar, numa visão interministerial, na Função Pública do Estado. Esses tipos fundamentais de empregos, definidos de uma maneira muito genérica, são designados por empregos de referência.

Os ministérios setoriais, a partir dos "rizomas" apresentados pelo Rime (com 261 empregos de referência, na edição de 2010), elaboram então os seus próprios referenciais, que são mais específicos que os do órgão central, desenvolvendo assim, nas suas respectivas áreas de atuação, a arborescência do referencial comum tanto no que diz respeito aos empregos, como às competências. Num ministério definem-se, assim, empregos-tipo (válidos para o ministério no seu conjunto) e, mais próximo da periferia, no nível das unidades de gestão de pessoas mais próximas aos servidores, são perfilados os empregos específicos (ou empregos "em si"), relacionados com a ocupação de postos de trabalho determinados.

É no nível operacional dessa arquitetura de empregos e competências arborescente que aparecem as fichas de postos. Essas fichas são definidas a partir dos empregos-tipo e utilizadas, em particular, para os recrutamentos. Elas contêm indicações mais específicas do que as fichas relativas aos empregos-tipo, incluindo, em particular, o posicionamento institucional e administrativo do posto de trabalho (o relacionamento com outros postos de trabalho), bem como sua localização geográfica e as missões, atividades e competências requeridas do ocupante.

Contudo, deve-se ressaltar que, entre os países da OECD selecionados por Op de Beeck e Hondeghem (2010) para análise comparativa, o governo francês é o único que não tem um modelo de competências essenciais centralizado, de uso geral.

\section{Reino Unido}

O Reino Unido, como a Suécia, foi um dos primeiros países da União Europeia a desenvolver referencias de competências para uso na administração pública nos anos 1980. Essa iniciativa, no entanto, não visava ao desenvolvimento de competências em todo o serviço civil (Civil Service) no Reino Unido, mas apenas a prescrição de competências para os integrantes da alta gestão, agrupamento de 
servidores públicos que depois passou a ser conhecido como Senior Civil Service (SCS). Os perfis profissionais eram prescritos nas dimensões qualidades pessoais e habilidades e utilizados para seleção de candidatos aos cargos em cada nível da alta gestão, treinamento e desenvolvimento na carreira (FARNHAM; HORTON, 2002).

O conceito de competências essenciais (core competencies) nasceu nesse prelúdio da gestão baseada em competências, referindo-se às competências requeridas dos integrantes da alta gestão. Em 1987, o modelo original evoluiu para um construto denominado Qualificação Vocacional Nacional (National Vocational Qualification - NVQ), também voltado para a qualificação de gerentes, mas dessa vez contando também com serviços de consultoria do mercado. Conforme Farnham e Horton (2002), os cursos de aperfeiçoamento previstos nessa iniciativa, buscando o desenvolvimento das competências gerenciais essenciais, consistiam de conteúdos relativos a competências de postos de trabalho e papéis e critérios pessoais, numa combinação de abordagens baseadas em padrões de referência e aspectos comportamentais.

O movimento pela competência no setor público britânico, como era de se esperar no momento de difusão das ideias reformistas da Nova Gestão Pública (New Public Management - NPM), não tinha uma diretriz central, sendo sua implementação totalmente descentralizada e fragmentada, em que cada órgão ou agência governamental decidia pelo uso ou não dessa tecnologia social, sobre qual metodologia deveria ser adotada e como deveria implementá-la. Esses autores asseveram, no entanto, que existiam claras evidências do uso disseminado de abordagens de gestão baseadas em competências em muitas áreas da política pública de pessoal britânica nos anos 1990.

Esse movimento evoluiu no Reino Unido desde então, numa base mais direcionada pelo Escritório do Gabinete do Primeiro Ministro (Cabinet Office), que estabeleceu a política a partir de alguns documentos-chave: Carta do Cidadão (Citizen's Charter, 1991); Desenvolvimento e Treinamento para Servidores Civis: um Construto para Ação (Development and Training for Civil Servants: a Framework for Action, 1996); e Modelo de Excelência de Negócio (Business Excellence Model, 1996). Esse último modelo teve como objetivo estabelecer parâmetros de qualidade para comparação do desempenho (benchmarking) das organizações públicas.

Farnham e Horton (2002) relatam que no final dos anos 1990 a maioria das agências revelava interesse na abordagem de gestão baseada em competências e que algumas tinham desenvolvido construtos (frameworks) de competências mais abrangentes. O Escritório do Gabinete, no entanto, não detinha nenhum registro sobre as agências que praticavam a gestão por competências nessa época, situação que motivou uma pesquisa temática empreendida por esses autores (relatada na respectiva obra referenciada neste artigo). 
O primeiro dado estatístico importante dessa pesquisa, realizada mediante o uso de questionários, revelava que $80 \%$ dos órgãos públicos da amostra ( $27 \%$ do universo de organizações que integravam o Civil Service) utilizavam construtos de competências. As áreas de gestão de pessoas de maior abrangência eram: desenvolvimento de pessoas, avaliação de pessoas e treinamento, sendo que poucas agências (13 num universo de 62) aplicavam critérios de competências em sistemas de remuneração. Entretanto, $75 \%$ das organizações pesquisadas aplicavam abordagens de competências de modo mais abrangente no ciclo de gestão de pessoas, além da capacitação e desenvolvimento.

Essa pesquisa também revelou um aspecto conceitual que, até o momento, ainda gera muita confusão no setor público: os modelos arbóreos de classificação de competências e suas linguagens. Farnham e Horton (2002) relatam que os dados sobre os números de competências definidos nos construtos dos órgãos britânicos causavam dificuldades de interpretação porque eles representavam modelos diversos de agregações, alguns empregando modelos em categorias (grades) e títulos (headings). Essa observação é importante porque geralmente se observa, no setor público brasileiro, alusões a categorias de competências como equivalentes às competências observáveis e não às competências observáveis em si, especialmente quando os interlocutores não conhecem as técnicas de redação de competências - como exemplo mais comum, atendimento ao público sem um contexto não se refere a uma competência tecnicamente observável, mas a uma categoria de competências que são desempenhadas de modo diverso e observáveis somente em contextos ou postos de trabalho específicos (no balcão, por meio de telefone, por correio eletrônico etc).

As metodologias de construção de modelos de competências variavam muito, mas as mais utilizadas, segundo essa pesquisa, eram Repertory Grid, Critical Incident Analysis, Benchmarking in Isolation, Focus Groups e combinações desses métodos. Farnham e Horton (2002) também relatam que os principais óbices à implementação da gestão por competências no Civil Service eram: a dificuldade de compreensão dessa tecnologia social de gestão pelos servidores; a ausência de comprometimento dos gerentes de linha; e a falta de apropriação e apoio da alta gestão. Essas conclusões coincidem com as de Costa e Almeida Junior (2013) e de Camões (2013) sobre os principais óbices à implementação da Política Nacional de Desenvolvimento de Pessoal (PNDP) no Sistema de Pessoal Civil da Administração Federal (Sipec), no Brasil, conforme o Decreto no 5.707, de 23 de fevereiro de 2006.

Os pesquisadores britânicos observaram que alguns órgãos que obtiveram êxito nessa etapa de inovação pioneira empregaram uma espécie de "régua" de avaliação com os comportamentos desejados e indesejados, definindo-se num 
extremo os comportamentos efetivos (effective behaviours) e desejados e, na outra extremidade da "régua", os comportamentos inefetivos (ineffective behaviours) e indesejados. Outros utilizaram uma técnica parecida, apresentando exemplos dos comportamentos desejados e indesejados em cada competência.

Em síntese, os resultados da pesquisa de Farnham e Horton (2002) mostram que, no final dos anos 1990, a maioria (95\%) dos órgãos do governo britânico tinha implantado ou estava em processo de implantação de modelos próprios de gestão por competências, e que era unanimidade a percepção da superioridade da gestão por competências, como tecnologia de gestão de pessoas, em relação ao modelo anterior. Os pesquisadores também descobriram que o processo de difusão dessa tecnologia social nos órgãos tinha sido ad hoc, com algumas agências contratando consultorias de mercado e outras contando apenas com consultorias dos departamentos vinculantes. Com base nos depoimentos dos gestores nos órgãos, as parcerias com os órgãos vinculantes parecem ter produzido resultados melhores, com alguns respondentes informando que as causas de seus problemas tinham sido justamente as consultorias de mercado.

Contudo, em relação às competências gerenciais, a realidade era completamente diferente, tendo o Escritório do Gabinete centralizado a elaboração e controle da aplicação de um modelo de competências prescritivas para o Senior Civil Service (SCS) em todos os órgãos públicos, que soma em torno de 3 mil servidores públicos no Reino Unido. Farnham e Horton (2002) ressaltam que o primeiro modelo britânico geral de gestão por competências para a alta gestão (originalmente para os três níveis hierárquicos mais elevados), elaborado em 1993, era holístico.

O interesse prioritário do governo britânico na gestão das competências executivas e gerenciais é evidente quando se resgata a evolução do construto de competências para a alta gestão. Em 1996, quando se criou o SCS, esse modelo passou a abranger mais dois níveis de gestão abaixo dos três originais e, em 1999, com um novo relatório propondo uma reforma no Civil Service (Report on Civil Service Reform), iniciou-se um novo projeto de gestão por competências para a alta gestão pública com a publicação do texto-base Modernising Government (Modernizando o Governo, de 1999). Esse projeto previa reformas radicais na própria composição do Civil Service, sua organização e práticas, com objetivo também de promover mudanças em sua cultura, de modo que o Civil Service se tornasse apto a liderar e implementar, com as competências essenciais necessárias (core competencies), um programa de mudanças para o aparelho de Estado.

Farnham e Horton (2002) relatam que a elaboração desse novo construto de competências para o SCS, com o sugestivo título Liderança para Resultados (Leadership for Results), consumiu 15 meses de um trabalho de consultoria 
executado por uma pequena empresa composta por ex-servidores do próprio Civil Service. Esse modelo se concentrava em comportamentos e não em conhecimentos e habilidades, justificando-se seus projetistas, em relação a essa abordagem adotada, que conhecimentos e habilidades eram requisitos exigidos dos servidores para o acesso aos cargos e não competências a serem observadas e desenvolvidas, e que os comportamentos é que descrevem como os conhecimentos e habilidades agregam valor aos serviços prestados pelos servidores. Os autores observam que essa doutrina de gestão para o SCS pretendia ser generalista e politicamente neutra, com aplicação em qualquer organização pública, privada ou do terceiro setor, destinando-se a promover uma convergência entre os mercados público e privado de executivos.

Em 2003, com a conclusão do construto de competências para a alta gestão pública (SCS), o governo britânico iniciou o desenvolvimento de outro construto de competências para todos os servidores do Civil Service, denominado Habilidades Profissionais para o Governo (Professional Skills for Government), abrangendo também os servidores excluídos no construto anterior. Esse construto, que se propunha a abranger todos os níveis de gestão, foi lançado em 2008 e se esperava sua introdução em cada departamento, pelo menos "aninhada" (embedded) nos construtos de competências existentes, até 2012 (OP DE BEECK; HONDEGHEM, 2010a).

Com base na arquitetura e modelo de gestão desse construto, as competências esperadas (prescritas) para os sete níveis hierárquicos mais elevados do Civil Service, cujos ocupantes compõem o Senior Civil Service (SCS), são elaboradas e controladas pelo órgão central, localizado na estrutura do Gabinete do Primeiro Ministro, enquanto as demais competências, por serem mais específicas, são elaboradas e utilizadas pelos departamentos e agências de modo descentralizado.

Historicamente, observa-se que a visão oficial de competências no setor público britânico se parece com um pêndulo, ora priorizando a dimensão comportamental, ora priorizando as dimensões relativas a conhecimento e habilidade, tanto em governos conservadores (mais gerencialistas), como em governos trabalhistas (mais burocráticos). O construto Professional Skills for Government alterou a tendência anterior do Modernising Government e reabilitou a ênfase nas dimensões de conhecimento e habilidade (OP DE BEECK; HONDEGHEM, 2010a).

Entretanto, a preocupação com os aspectos comportamentais dos servidores públicos britânicos parece ser uma constante, mesmo com novas orientações nos construtos de competências. O Código do Serviço Civil (Civil Service Code), que se compara, de certo modo, aos estatutos de servidores públicos no Brasil, é um exemplo dessa ênfase comportamental, em que se encontram os quatro valores essenciais (core values) exigidos de todos os integrantes do Civil Service: integridade, honestidade, objetividade e imparcialidade. 
Outro movimento recente observado na gestão de pessoas do governo britânico é o da segmentação da força de trabalho, previsto no documento Estratégia de Habilidades do Reino Unido (UK Skills Strategy). Esse conceito é definido como o agrupamento de servidores em segmentos com características comuns, tais como função, especialidade e local de lotação. A segmentação é considerada um meio de se propiciar um planejamento da força de trabalho mais adequado às necessidades dos órgãos, com os seguintes benefícios esperados também para os servidores (OP DE BEECK; HONDEGHEM, 2010a): processos de recrutamento mais focados em habilidades adequadas às necessidades dos órgãos; maior facilidade de retenção de talentos a partir das oportunidades de desenvolvimento e de mobilidade setorial no trabalho; caminhos mais claros na carreira; maior empregabilidade interna e externa; e engajamento mais próximo de suas próprias comunidades profissionais.

Segundo Sanches (2013), com a formação de um novo governo de coalizão no Reino Unido em 2010, de maioria conservadora, o "pêndulo" doutrinário do modelo de competências voltou a se mover em direção ao gerencialismo. O movimento recente, baseado no documento Novo Construto de Competência do Civil Service para 2012-2017 (New Civil Service Competency Framework 2012-2017), lançado em 2012, integra um plano de reforma da função pública que incluiu a substituição do construto anterior (Professional Skills for Government). Este novo construto de competências também prevê sua aplicação a todos os membros do Civil Service, revelando-se uma tendência de unificação de referenciais de competências no Reino Unido.

Esse novo referencial britânico, conforme sua orientação política de origem, busca promover comportamentos voltados à produção de valor acrescido real aos serviços públicos, com ênfase em prazos de entrega e uma mentalidade mais comercial, na doutrina conhecida como value for money. O documento publicado (UKCSHR, 2012) revela um esmero técnico incomum nesse tipo de referencial ao confirmar a utilidade da "régua de efetividade" na descrição das competências. O construto é focado em categorias de competências voltadas para resultados, com dez competências classificadas em três grandes grupos (ou clusters) de ações intituladas como: Strategic Cluster - Setting Direction (Cluster Estratégico - Estabelecendo a Direção); People Cluster-Engaging People (Cluster de Pessoas - Engajando as Pessoas); e Performance Cluster-Delivering Results (Cluster de Desempenho - Entregando Resultados).

A Figura 2 indica quais são as competências essenciais exigidas dos servidores. O que essas competências têm em comum, além do foco em resultados, são os chamados Valores do Serviço Civil (Civil Service Values), restando claro, portanto, que se trata de uma nova orientação política sobre o que o governo britânico espera de seus servidores públicos nos próximos anos. 
Figura 2: Construto de Competências do Civil Service no Reino Unido

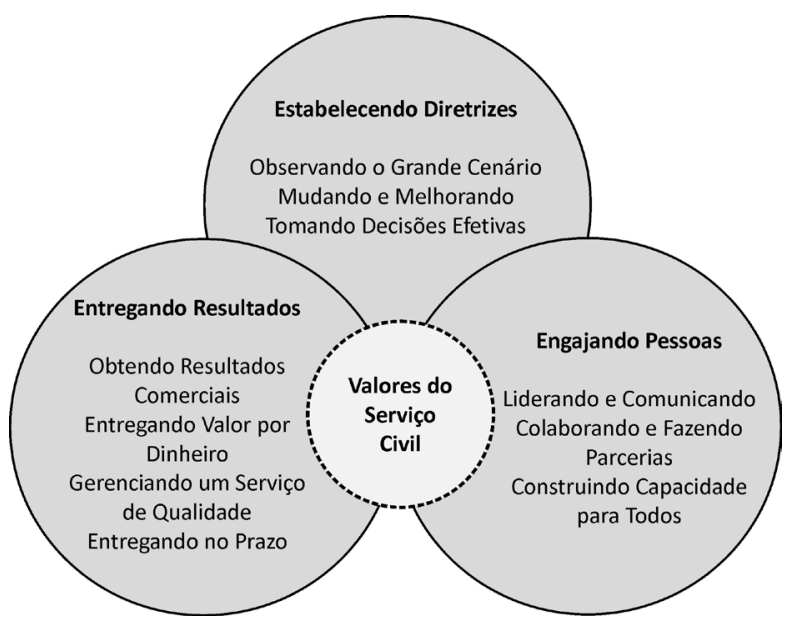

Fonte: UKCSHR, 2012.

Outro ponto forte desse construto centralizado de competências reside no empoderamento do método científico nos processos de tomada de decisões, na medida em que torna obrigatória a apresentação de evidências nos esclarecimentos de problemas e nas proposituras de soluções pelos servidores públicos e membros da alta gestão (SCS). Entre os valores a serem desenvolvidos no serviço público britânico, encontra-se o predomínio do poder do argumento em detrimento do argumento do poder, representando um avanço notável da gestão democrática da coisa pública.

\section{Conclusões e desafios aos governos brasileiros}

As experiências dos países da OECD na adoção de modelos de gestão por competências para o setor público revelam três características em comum, que permitem, talvez, uma generalização científica acerca das variáveis desse fenômeno. O primeiro aspecto em comum é o contexto nacional de crise econômica, com impactos nos sistemas políticos e sociais dos países; o segundo aspecto é a vontade política de mudança nos modelos de gestão pública, que se materializa como componente dos pacotes de políticas públicas concebidos em resposta a essas crises; e o terceiro aspecto é a preocupação prioritária dos governos com os estamentos executivos e gerenciais, entendendo que o desenvolvimento de lideranças é crucial para as mudanças.

Com esse cenário de crises econômicas que, muitas vezes, se prolongam por décadas, a tecnologia social de gestão por competências nos países da OECD se apresenta como um instrumento de reformas estruturantes e não apenas pontuais, 
"cosméticas", da administração pública. Essas iniciativas propõem a realização de reformas institucionais principalmente no ethos do setor público (entendido como as crenças e valores essenciais), promovendo mudanças de base nas instituições.

Essa dimensionalidade das mudanças desejadas é expressa nas próprias metacompetências essenciais adotadas, prescritivamente (no sentido top down), pelos governos, por meio de seus órgãos centrais de gestão de pessoal. As metacompetências refletem desejos que se reportam aos valores políticos dos governos eleitos e não, necessariamente, às competências disponíveis nas organizações públicas - o que, de certo modo, reflete também uma visão de futuro para o País e não o status quo da burocracia no presente.

O setor público brasileiro, no entanto, apresenta alguns aspectos institucionais problemáticos não encontrados nos países mais desenvolvidos da $O E C D$, que precisam ser avaliados num contexto de gestão por competências. Em relação à ética pública, por exemplo, comportamentos políticos seculares teriam que ser mudados em face de valores democráticos essenciais, tais como a necessidade de objetiva comprovação de competência profissional para promoção de servidores nas carreiras e para o apontamento de pessoas a cargos da alta gestão nas organizações públicas. Esses novos valores, que se referem a uma nova ética para o setor público, requerem uma associação sinérgica de dois instrumentos tecnológicos de gestão: avaliação de competências e de desempenho, que são duas faces da mesma moeda.

Essa nova ética baseada em competências, para a gestão de pessoas, também exigiria uma reflexão pragmática sobre o atual modelo geral de recrutamento e seleção de candidatos para as carreiras no setor público. O modelo vigente, baseado no instituto do concurso público, permite apenas a avaliação de conhecimentos e a valoração de títulos acadêmicos, ignorando qualquer habilidade e perfil comportamental do candidato, salvo as exceções de praxe (como nos casos das carreiras policiais em geral e de alguns cargos com funções operacionais manuais, como o de gari).

Embora tenha o inegável mérito democrático de abrir oportunidades para todos os cidadãos formalmente aptos e tornar o processo seletivo tecnicamente criterioso, transparente e auditável, o atual modelo de concurso público não permite uma avaliação completa da competência do candidato e não permite, também, a seleção de perfis para funções executivas e gerenciais.

Outra consequência do concurso público baseado apenas em conhecimento acadêmico é que esse modelo esvazia os argumentos corporativos de servidores públicos que, muitas vezes, propõem uma reserva de mercado para si mesmos nos apontamentos para cargos executivos e gerenciais. Considerando-se que o processo seletivo original (concurso para ocupação de cargos efetivos) não tem como objetivo 
o recrutamento de perfis gerenciais, e, mais adiante nas carreiras, os servidores efetivos investidos em funções gerenciais geralmente não são avaliados nesse sentido, como seriam identificados nos órgãos públicos os potenciais gerentes?

E o que dizer do atual sistema de apontamento para os cargos de direção e assessoramento superiores, baseados unicamente na confiança? Lewis (2005), com base num indicador de eficiência para avaliação de resultados de agências do governo dos EUA, demonstra, empiricamente, que o critério da confiança utilizado nos apontamentos para funções executivas nos governos é autocontido, pois esse atributo personalístico não pode ser desdobrado em outros atributos, tais como eficiência, ou adotado como meio de se obter melhor desempenho das organizações públicas de um ponto de vista republicano. Como impactos negativos dessa ética, ele observa que a politização resulta em redução da competência das agências, afeta sua capacidade e eficiência e reduz o moral da organização e o capital humano.

É de se esperar, também, resistências à gestão baseada em competências devido ao aparente conflito normativo entre competências de cargos e de postos de trabalho. A exemplo de países mais "napoleônicos" da OECD, como França e Bélgica, esses dois conceitos não são antitéticos, mas complementares, podendo conviver harmoniosamente. As competências dos postos de trabalho e de seus ocupantes não devem afrontar as competências legais dos cargos, que geralmente são mais genéricas, mas devem constituir detalhamentos das competências dos cargos em contextos específicos de trabalho efetivo nas organizações públicas.

Outros dois aspectos importantes, reconhecidos a partir das experiências dos países da OECD, é que não existe, e talvez nunca possa existir, um modelo universal de competências para o setor público, e que os modelos de competências são desenvolvidos com base em processos experimentais, com tentativas e erros (OP DE BEeCK; HONDEGHEM, 2010a).

Em suma, conclui-se que a gestão por competências constitui um verdadeiro "estilo de vida" de uma organização que planeja sua força de trabalho, recruta e seleciona talentos, avalia o desempenho individual, reconhece, promove, remunera e substitui seus executivos, gerentes e colaboradores com base em competências.

\section{Referências bibliográficas}

Belgique. Le Gouvernement Fédéral. Arrêté royal du 25 octobre 2013 relatif à la carrière pécuniaire des membres du personnel de la fonction publique fédérale (Real Decreto de 25 de outubro de 2013 relativo às tabelas pecuniárias do pessoal da função pública federal). Disponível em: http://www.fedweb.belgium.be/fr/ binaries/20131025_nieuwe_loopbaan-nouvelle_carri\%C3\%A8re_tcm119-236933. pdf. Acesso em: 20 dez. 2014. 
BRANDÃo, Hugo Pena. Mapeamento de competências: métodos, técnicas e aplicações em gestão de pessoas. São Paulo: Atlas, 2012.

CAMÕES, Marizaura Reis de Souza. Análise do processo de implementação da Política Nacional de Desenvolvimento de Pessoal. 2013. Dissertação de Mestrado. UnB, Brasília, 2013. Disponível em: <http://www.ppga.unb.br/...marizaura-reis-desouza.... A Acesso em: 10 maio 2013.

COSTA, Thiago Dias; ALMEIDA JUNIOR, João Cauby de. Mapeamento de Competências Individuais dos Servidores Técnico-Administrativos da Universidade Federal do Pará. VI CONGRESSO CONSAD DE GESTÃO PÚBLICA, Brasília (DF), 16 a 18 de abril de 2013. Disponível em: <http://www.escoladegoverno.pr.gov.br/.../2013/V_CONSAD/VI_ CONSAD/017.pdf.> Acesso em: 10 jan. 2014.

FARNHAM, David; HoRTON, Sylvia. HRM Competency Frameworks in the British Civil Service. In: HorTon, Sylvia; HondegheM, Annie; FARnhAM, David (Eds.). Competency management in the public sector: European variation on a theme. University of Portsmouth, Institut voor de Overheid, IOS, 2002, p. 33-47.

GethA-TAYLOR, Heather. Competency management in the US Federal Government. K. U. Leuven, Public Management Institute, 2010. Disponível em: <http://soc. kuleuven.be/io/ned/project/pdf/hrm27_country_report_us.pdf.> Acesso em: 7 jan. 2014.

Hondeghem, Annie; PARYs, Myriam. Competency management in Belgium: the Flemish and federal governments on the move. In: HORTON, Sylvia; HONDEGHEM, Annie; FarnhaM, David (Eds.). Competency management in the public sector: European variation on a theme. University of Portsmouth, Institut voor de Overheid, IOS, 2002. p. 49-64.

JEANNOT, Gilles; LICHTENBERGER, Yves. What competency management in the French Civil Service? In: Horton, Sylvia; Hondeghem, Annie; Farnham, David (Eds.). Competency management in the public sector: European variation on a theme. University of Portsmouth, Institut voor de Overheid, IOS, 2002, p. 123-134.

LASSANCE JR., Antonio E.; Mello, Claiton José; BARBosA, Eduardo José Siqueira; JARDIM, Fabiana Alves; BRANDÃo, Flávio Cruvinel; NovAES, Henrique Tahan; RutKowskI, Jacqueline; PenA, Jacques de Oliveira; PedreIRA, Juçara Santiago; Dowbor, Ladislau; Otero, Martina Rillo; Singer, Paul; DAgnino, Renato; LIANZA, Sidney; BAVA, Silvio Caccia; KRUPPA, Sonia Maria Portella. Tecnologia social: uma estratégia para o desenvolvimento. Rio de Janeiro: FBB, 2004.

LEWIS, David E. Presidents and the politicization of the United States Federal Government, 1988-2004. ANNUAL MEETING OF THE AMERICAN POLITICAL SCIENCE ASSOCIATION, 2005, Washington, DC. Disponível em: <http://www.dartmouth. edu/ govt/docs/Lewis.pdf.> Acesso em: 10 jan. 2014.

LUCIA, Anntoinette D.; LEPSINGER, Richard. The art and science of competency models: pinpointing critical success factors in organizations. San Francisco (CA, USA): Jossey-Bass/Pfeiffer, 1999.

OP DE BEECK, Sophie; HondegheM, Annie. Managing competencies in government: state of the art practices and issues at stake for the future. OECD, 2010a. Disponível 
em: <https://portalsipec.planejamento.gov.br/...dialogos-setoriais...-federal.> Acesso em: 4 out. 2013.

Competency management in the Belgian Federal Government. K.U. Leuven, Public Management Institute, 2010b. Disponível em: <http://soc.kuleuven. be/io/ned/project/.../hrm27_country_report_belgium.pdf.> Acesso em: 21 dez. 2013.

PETERS, B. Guy. The politics of bureaucracy: an introduction to comparative public administration. 6. ed.. London and New York: Routledge, 2010.

SANCHES, Adérito Alain. A gestão por competências nas administrações públicas europeias e os sistemas de informação que apoiam essa gestão-França, Bélgica e Reino Unido. Relatório de Consultoria. Brasília: SEGEP/MP, 2013. Disponível em: <https:// portalsipec.planejamento.gov.br/arquivos/dialogos....> Acesso em: 10 jan. 2014.

United Kingdom. Civil Service Human Resources (UKCSHR). Civil Service Competency Framework 2012-2017. UK Civil Service Human Resources, 2012. Disponível em: <https://portalsipec.planejamento.gov.br/arquivos/dialogos-setoriais....> Acesso em: 10 jul. 2013.

United States Of America/Office Of Personnel Management (USOPM). Multipurpose Occupational Systems Analysis Inventory - Close-Ended (MOSAIC) Competencies. USOPM, January 2013. Disponível em: <http://www.opm.gov/ policy-data-oversight/assessment-and-selection/competencies/mosaic-studycompetencies-master-list.pdf.> Acesso em: 30 dez. 2013.

WESTMAN, Mi Sook Park. Does culture matter in competence management? Transforming barriers to enablers. Xlibris, 2012.

Ethel Airton Capuano

Doutor em Ciência da Informação pela Universidade de Brasília (UnB). É também servidor público federal membro da carreira de Especialista em Políticas Públicas e Gestão Governamental (EPPGG), desde 1990 (1a turma). Contato: eacapuano@terra.com.br 